\title{
Diabetes and heart failure: time for a new approach
}

\section{Opinion}

Diabetes (DM) has always been a thorn in the side for heart disease patients. They have higher rates of death, added risk of stent restenosis and approximately $20 \%$ have asymptomatic myocardial ischemia. Moreover, $80 \%$ of DM patients die of cardiovascular (CV) disease and present an increased risk of developing heart failure, which is becoming a modern epidemic. ${ }^{1,2}$

Treating the heart failure patient is never easy, and it is well known that comorbidities raise the risk not only of death but also of heart failure hospitalization (HFH), influencing the prognosis negatively. ${ }^{3}$ When the SGLT2 showed a reduction in cardiovascular mortality on patients with established atherosclerotic disease, it brought enthusiasm to the cardiology community. We were just waiting for diabetes drugs that could influence positively the prognosis of the natural history of cardiovascular disease. We had some neutral drugs such as DPP4 and other ones that required caution due to the risk of $\mathrm{HFH} .{ }^{4-8}$

Sometimes when we are aiming at one target, we end up hitting something else. One of the most significant results was $\mathrm{H}$ decrease by $35 \%$ in EMPAREG, $33 \%$ in CANVAS and 39\% in CVD Real, showing a promising approach to diabetic patients concerning heart failure events. ${ }^{4,7,8}$

The recently published DECLARE TIMI-58, which is a sub-study with heart failure patients, ratified this data. Of the global population of 17,160 patients, only $3.9 \%$ had heart failure with reduced ejection fraction ( $\mathrm{HFrEF}$ ) defined as $\mathrm{EF}<45 \%$, and this group had a reduction of $\mathrm{CV}$ death and $\mathrm{HFH}$ of $38 \%$, HFH of $36 \%$ and $\mathrm{CV}$ death of $45 \%$. No reduction was observed for non-HFrEF patients. ${ }^{9}$

Based on all this data, very soon SGLT2 is going to be incorporated to the basic medical therapy for patients with DM and HFrEF.

\section{Acknowledgments}

None.

\section{Conflicts of interest}

The author declares there is no conflict of interest.

\section{Funding}

None.

\section{References}

1. Young LH, Wackers FJ, Chyun DA, et al. Cardiac outcomes after screening for asymptomatic coronary artery disease in patients with type 2 diabetes: the DIAD study: a randomized controlled trial. JAMA. 2009;301(15):1547-1555.
Volume 6 Issue 3 - 2019

\author{
Renato Kaufman \\ Instituto Estadual de Cardiologia Aloisio de Castro, Rio de Janeiro, \\ Brazil \\ Correspondence: Renato Kaufman, MD, MSc, PhD, Instituto \\ Estadual de Cardiologia Aloisio de Castro, Rio de Janeiro, Brazil, \\ Email renatokaufman@gmail.com
}

Received: July 22, 2019 | Published: August 27, 2019

2. Levine GN, Bates ER, Blankenship JC, et al. 2011 ACCF/AHA/SCAI Guideline for percutaneous coronary intervention: a report of the American College of Cardiology Foundation/American Heart Association Task Force on Practice Guidelines and the Society for Cardiovascular Angiography and Interventions. Circulation. 2011;124(23):574-651.

3. Sharma A, Zhao X, Hammill BG, et al. Trends in Noncardiovascular Comorbidities Among Patients Hospitalized for Heart Failure: Insights From the Get With The Guidelines-Heart Failure Registry. Circ Heart Fail. 2018;11(6):004646.

4. Zinman B, Wanner C, Lachin JM, et al. Empagliflozin, cardiovascular outcomes, and mortality in type 2 diabetes. $N$ Engl J Med. 2015;373(22):2117-2128.

5. White WB, Cannon CP, Heller SR, et al. Alogliptin after acute coronary syndrome in patients with type 2 diabetes. $N$ Engl $\mathrm{J} \mathrm{Med}$. 2013;369(14):1327-1335.

6. Masoudi FA, Inzucchi SE, Wang Y, et al. Thiazolidinediones, metformin, and outcomes in older patients with diabetes and heart failure: an observational study. Circulation. 2005;111(5):583-590.

7. Neal B, Perkovic V, Mahaffey KW, et al. Canagliflozin and cardiovascular and renal events in type 2 diabetes. N Engl J Med. 2017;377(7):644-657.

8. Kosiborod M, Cavender MA, Fu AZ, et al. Lower risk of heart failure and death in patients initiated on sodium-glucose cotransporter-2 inhibitors versus other glucose-lowering drugs: the CVD-REAL Study (Comparative Effectiveness of Cardiovascular Outcomes in New Users of SodiumGlucose Cotransporter-2 Inhibitors). Circulation. 2017;136(3):249-259.

9. Kato ET, Silverman MG, Mosenzon O, et al. Effect of Dapagliflozin on Heart Failure and Mortality in Type 2 Diabetes Mellitus. Circulation. $2019 ; 139(22): 2528-2536$ 